\title{
THE GRADIENT PROJECTION ALGORITHM WITH ADAPTIVE MUTATION STEP LENGTH FOR NON-PROBABILISTIC RELIABILITY INDEX
}

\author{
Zhaoping Tang, Jin Qin, Jianping Sun, Biao Geng
}

Original scientific paper

Aiming at the problems of selection parameter step-size and premature convergence that occurred when searching the local area in the optimal design of adaptive gradient projection algorithm in this paper, adaptive variable step-size mechanism strategy and adaptive variable step-size mechanism were established. They were introduced into the gradient projection algorithm, and were used to control iteration step length. Through the examples of nonprobabilistic reliability index, it can be showed that the method could quickly and accurately calculate the reliability index when the model had multiple variables and complex limit state function. To compare and contrast this algorithm with the simple gradient projection algorithm, this algorithm is not sensitive to the initial point position. And it not only takes into account both local performance and global search ability, but also has fast convergence speed and high precision. So it is an efficient and practical optimization algorithm.

Keywords: adaptive; gradient projection algorithm; mutation step length; non-probabilistic reliability

Algoritam gradijenta projekcije s prilagodljivom mutacijom duljine koraka za indeks nevjerojatnosne pouzdanosti

Izvorni znanstveni članak

Ciljajući na probleme odabira parametra korak-veličina i prerane konvergencije koja se dogodila kod pretraživanja na lokalnom optimalnom području u dizajnu adaptivnog gradijenta projekcijskog algoritma u ovom radu, uspostavljena je strategija mehanizma prilagodljive varijable korak-veličina i mehanizma prilagodljive promjenljive varijable korak-veličina. Uvedene su u algoritam gradijenta projekcije i upotrebljene za reguliranje duljine koraka iteracije. Kroz primjere indeksa nevjerojatnosne pouzdanosti može se pokazati da se tom metodom može brzo i točno izračunati indeks pouzdanosti kad model ima višestruke varijable i složenu funkciju graničnog stanja. Kod komparacije i kontrastiranja ovog algoritma s algoritmom gradijenta projekcije, taj algoritam nije osjetljiv na položaj polazne točke. Tako on ne samo da uzima u obzir i lokalnu performansu i globalnu sposobnost pretraživanja već posjeduje i veliku brzinu konvergencije i visoku preciznost. Stoga je to učinkovit i praktičan algoritam optimizacije.

Ključne riječi: algoritam gradijenta projekcije; mutacija duljine koraka; nevjerojatnosna pouzdanost; prilagodljiv

\section{Introduction}

Reliability problem derives from uncertainties existing in the engineering. The probabilistic model cannot be defined for the reason of no statistical properties parameters. And the superiority membership function is difficult to be determined due to the lack of adequate data. In view of the fact that the parameters' ranges or limits are easy to be determined, it is ideal to choose non-probabilistic reliability method based on interval analysis [1].

Over-estimated interval expansion is an important problem in interval analysis [2]. The root cause of the problem is the basic hypothesis in interval arithmetic: all parameters participating in computing are mutually independent, and their values change independently without mutual influence in the interval range. However, in fact, this assumption often may not be tenable. There are classes of approaches for solving well the overestimation interval expansion problem: exact methods and approximate methods. Exact methods mainly include: (1) Transformation into optimization problem. It disposes of the problem by transforming interval computation into traditional programming problem. Under the assumption that all the interval variables are completely independent, to transform into optimization problem, establish the corresponding pure mathematical model, the exact range of function value can be generally gotten, although some transformed optimization problems calculations are complex. (2) Use interval combination method. According to monotone theorem of real-valued function, the upper and lower bound of function can be obtained by the function calculation values corresponding to end- values of independent variables [3]. If there are multiple independent variables, by arranging or combining the upper and lower bound of each independent variable, the accurate interval range of function value can be obtained.

Sometimes, if the limit state function is complicated and Variable is various, the calculated amount of exact solution would be excessive, or even incalculable. A computer program algorithm will undoubtedly bring convenience to rapidly and accurately solve nonprobabilistic reliability problems with complex multivariable functions. On account of the explicit physical significance and rapid iteration [4], gradient projection method has been applied to solving reliability indexes of interval model [5]. Li Shijun [6] proved its feasibility and effectiveness by practical example. However, his study found that if gradient projection method was only adopted, the most calculated probable failure point would rely on the selection of initial point. It is difficult to ensure ideal accuracy of the iterative convergence point. To combine gradient projection with space dimension reduction method, the efficient search can be terminated on actual target point. However, its searched dangerous point would surely be confined to angular points of multidimensional cube box model composed by standardized interval variables. Some

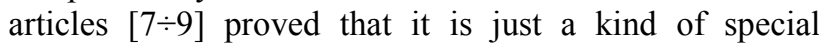
circumstances, not universal.

In this paper, adaptive step-size strategy and mutation step-size mechanism were introduced into the gradient projection algorithm. In the process of iteration, the algorithm could automatically choose step strategy in terms of the actual situation in the solving process. When the search turned into local optimal area as well as the 
iteration appeared premature convergence, it could adaptively mutate step length and help the next search to get rid of local optimal area. In this way, it effectively avoided premature convergence and improved the global optimization capabilities of the algorithm. Furthermore, by the example of solving non-probabilistic reliability indexes, it is showed that the algorithm integrates the advantages of gradient projection algorithm and adaptive algorithm. It not only takes into account both local performance and global search ability, but also has high precision to dispose the optimization problem of highdimensional and complex non-probabilistic reliability.

\section{Interval reliability index}

Assuming $x=\left(x_{1}, x_{2}, \ldots, x_{n}\right)$ was a vector composed of interval variables which could affect structure function. The value range of $x$ could be expressed as $x \in x^{I}=\left[x^{l}, x^{u}\right]$. Then, based on function $M=g(x)=g\left(x_{1}, x_{2}, \ldots, x_{n}\right)$, the structure non-probabilistic reliability index $\eta$ could be expressed as:

$\eta=M^{c} / M^{r}$

In the formula, $M^{c}$ and $M^{r}$ were respectively the centre and radius of interval $M$.

Introducing standardized interval vector $\delta=\left(\delta_{1}\right.$, $\left.\delta_{n}\right), \delta \in C_{\left|\delta_{i}\right| \leq 1}^{n} \quad, \quad$ symmetric convex domain $C_{\left|\delta_{i}\right| \leq 1}^{n}=\left\{\left(\delta_{1}, \delta_{2}, \cdots, \delta_{n}\right):\left|\delta_{i}\right| \leq 1,(i=1,2, \cdots, n)\right\}$, interval vector $x$ could be standardized.

$x=x^{c}+x^{r} \delta$

In the formula, $x^{c}$ and $x^{r}$ were respectively the centre and radius of interval $x$. Replacing $x$ with $\delta$, performance function can be converted into equivalent function of standardized interval vector $\delta$ :

$$
M=G(\delta)=G\left(\delta_{1}, \delta_{2}, \cdots, \delta_{n}\right)
$$

At the same time, expansion space of $\delta$ can be got:

$$
C_{\delta}^{\infty}=\left\{\left(\delta_{1}, \delta_{2}, \cdots, \delta_{n}\right): \delta_{i} \in(-\infty,+\infty),(i=1,2, \cdots, n)\right\}
$$

Based on infinite norm, $\eta$, the interval reliability index, should be defined as the shortest distance from the origin to the failure surface measured by infinite norm \|\|$_{\infty}$ in the expansion space $C_{\delta}^{\infty}$ of standardized vector $\delta . \eta$ could be denoted as:

$$
\eta=\min \left\{\|\delta\|_{\infty}\right\}=\min \left\{\max \left\{\left|\delta_{1}\right|,\left|\delta_{2}\right|, \cdots,\left|\delta_{n}\right|\right\}\right\}
$$

Under the constraint:

$$
M=G\left(\delta_{1}, \delta_{2}, \cdots, \delta_{n}\right)=0
$$

It was apparent from these that the solving process of reliability index measured by infinite norm is an essentially optimization problem with equality constraint.

\section{Background introduction of gradient projection algorithm}

\subsection{Gradient algorithm and its improvement}

In 1847, Cauchy put forward gradient method [9], which was a minimization algorithm taking negative gradient direction as the search direction, in which objective function value could be expected to fall at the fastest rate. In unconstrained optimization problems solving, the method has some advantages, such as simple, much less computations, small store capacity, low request to initial point, and good global convergence. The gradient method reflects a local property of objective function. Seen from the local angle, descent direction is a truly fastest descent direction of objective function value. However, looked from the global angle, at dealing with some complicated nonlinear optimization problems, the gradient method only has Q-linear convergence. Because the optimization procedure adopts "zigzag pattern" to approach the minimum point, the searching needs to goes through a lot of detours, even if the moving distance toward the minimum point is not too long. It has greatly made the convergence rate to slow down.

In order to improve the performance of algorithm, the gradient algorithm has been made a variety of improvements. Barzilai and Borwein [10] proposed twopoint step-size gradient method, which was also called BB gradient method. It not only made general functions to achieve local R-linear convergence, but also achieve $\mathrm{R}$ super-linear convergence at arbitrary initial point in twodimension convex quadratic objective functions. The method immensely improved convergence speed, but it could not ensure that the search showed a declined tendency to each iteration function value. Dai [11] proved that cross-step (AS) gradient algorithm integrated both of the advantages. It avoided saw-tooth phenomenon. Furthermore, under the positive semi-definite system, freely given the initial point, all two-dimension functions had Q super-linear convergence with two steps, while all arbitrary dimensions functions had R-linear convergence.

In the 1950s, Hestenes and Stiefel proposed linear conjugate gradient method (HS algorithm) [12]. Fletcher and Reeves [13] put forward non-linear conjugate gradient method (FR algorithm) in 1960s. Subsequently, based on FR algorithm, a variety of conjugate gradient methods and hybrid conjugate gradient methods were proposed, such as PRP algorithm, LS algorithm, CD algorithm, DY algorithm, and modified PRP algorithm proposed by Yuan [14]. All these algorithms have conjugate property in nature. Combined conjugacy with gradient algorithm, to construct a set of conjugate direction by use of gradient of known points, and seek for the minimal point along the direction, conjugate gradient method overcomes the disadvantage of gradient method at slow convergence speed, and has super-linear quadratic convergence rate with $n$ steps. Generally speaking, methods of PRP, LS and HS have superior numerical performance; however, their convergence is not ideal. In contrast, FR, CD and DY methods have good 
convergence but poor numerical performance, which is hard to balance sufficient descent and global convergence.

In view of the case with constraint, non-feasible points may be obtained by search along the negative gradient direction. In 1960, Rosen put forward the gradient projection algorithm. When iteration point was in the feasible region, negative gradient of objective function should be taken as search direction. If iteration point was on the boundary of the feasible region, negative gradient projection on the boundary of the feasible region should be set as the direction, so as to ensure the constructed direction is feasible and declining.

\subsection{Gradient projection algorithm}

Gradient project algorithm belongs to line search method, both search direction $d_{k}$ and step size $\alpha_{k}$ are fundamental quantities, iterative scheme is $\delta^{k+1}=\delta^{k}+\alpha_{k} d_{k}$. Due to non-probabilistic reliability function being usually a non-linear function, constraint equations $G\left(\delta_{1}, \delta_{2}, \cdots, \delta_{n}\right)=0$ can also be spread at the iteration point $\delta_{k}$ and the linear items are chosen, i.e. to transform non-linear constraints into linear constraints at the iteration points, then to substitute the spreading surface for limit state surface of performance function, project negative gradient direction into the surface by means of projection matrix, the search direction $d_{k}$ can be constructed. If linear search point $\delta^{(0),(\mathrm{k}+1)}$ is not on limit state surface, quasi-Newton iteration must be used for dragging search point back to the surface $G\left(\delta_{1}, \delta_{2}, \cdots, \delta_{n}\right)=0$. The specific process is shown in Fig. 1.

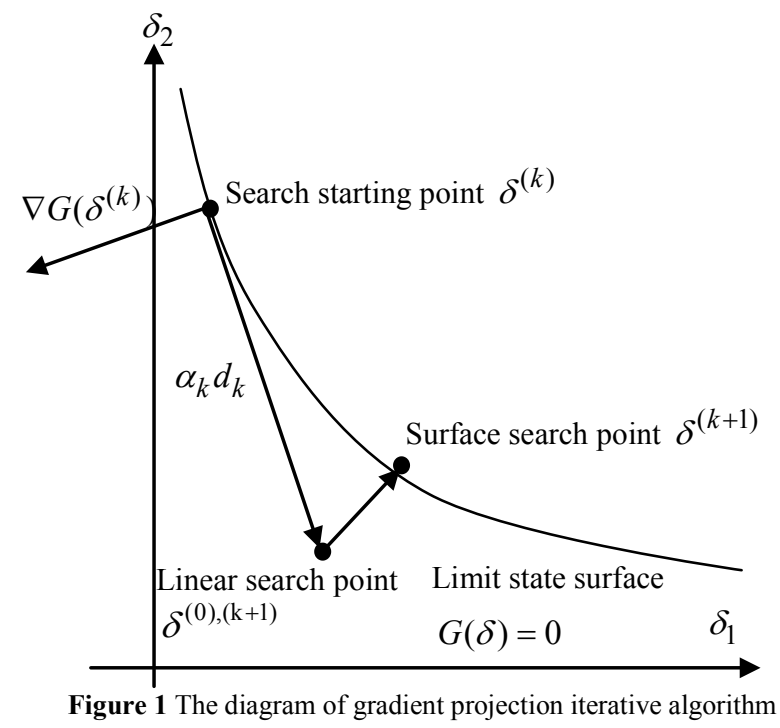

Aiming at the solving of non-probabilistic reliability indexes, assuming the objective function is $\min f(\delta)=\max \left\{\left|\delta_{1}\right|,\left|\delta_{2}\right|, \cdots,\left|\delta_{n}\right|\right\}$, that is to search the point owned the minimum in the maximum absolute value of coordinate component on the standardized failure surface. The value is only connected with the point coordinate component, and the analytical expression does not exist. It is hard to give negative gradient direction of objective function. So the traditional gradient projection algorithm cannot be directly used for the solving of nonprobabilistic reliability index. According to the mathematical meaning of gradient, the similar gradient vector of objective function should be constructed [6]

$\nabla f\left(\delta^{(k)}\right)=(0, \cdots, \pm 1,0, \cdots, 0)^{\mathrm{T}}$

In the formula (7), \pm 1 locate in the corresponding position where the coordinate component of point $\delta^{(k)}$ has the maximum absolute value, and 1 denotes the positive component, -1 denotes the negative component.

Taking $\nabla f\left(\delta^{(k)}\right)$ as the gradient of objective function $f(\delta)$ in the position $\delta^{(k)}$, and projecting it onto the surface (or curve) on the basis of the gradient projection algorithm, we could determine the search direction $d^{(k)}$.

$d^{(k)}=-\left[I-\frac{\nabla G^{\mathrm{T}}\left(\delta^{(k)}\right) \nabla G\left(\delta^{(k)}\right)}{\left|\nabla G\left(\delta^{(k)}\right)\right|^{2}}\right]\left[\nabla f\left(\delta^{(k)}\right)\right]$

It is obvious that $d^{(k)}$ meets $\left[\nabla G\left(\delta^{(k)}\right]\left[d^{(k)}\right]=0\right.$. That means search is along the tangent directions of failure surface. Meanwhile, $d^{(k)}$ satisfies the in equation $\left[\nabla f\left(\delta^{(k)}\right)\right]\left[d^{(k)}\right]<0$, i.e. it points to the descent direction of objective function.

For general iterative search algorithms, choosing properly the initial point, iteration convergence can be made rapidly and the desired accuracy can be achieved. But the choice of initial point depends on familiarity with research object and experience in engineering. As studied algorithm, selection condition of the initial point is expected to be broad. Therefore, the algorithm relaxes restrictions on the initial point, as long as initial point fell upon the limit state surface, i.e. it satisfied the constraint equation $G\left(\delta_{1}, \delta_{2}, \cdots, \delta_{n}\right)=0$.

\subsection{Adaptive step-size strategy and mutation step-size mechanism 3.3.1 Adaptive step-size strategy}

McCormick and Tapia found that gradient projection algorithm uses precise step-size rule in research and needs large computational quantity, so it was rarely adopted [15]. Hager and Park believed that only in some difficult problems with simple constraints, precise step-size rule could be used to make iteration point jump out from a neighbourhood of local minimum point and turn to the global minimum point [16].

In the complex constrained optimization, which does not usually use precise step-size rule, premature convergence phenomenon may occur in gradient projection algorithm after local optimum is reached. Compared with other step-size strategies, adaptive stepsize strategy has a higher convergence performance. In the light of the previous iterative information, it adjusts 
the search step in the monotonous way. So the strategy can make search step not only decrease but also increase. Armijo-Goldstein strategy, the common imprecise onedimensional search strategy, obtains iteration step by onedimensional search each time. It ensures that the objective function value has a satisfactory deduction. But objective function must be differentiated in iterative operation each time. The non-probabilistic reliability objective function, $\min f(\delta)=\max \left\{\left|\delta_{1}\right|,\left|\delta_{2}\right|, \cdots,\left|\delta_{n}\right|\right\}$, is not easy to be differentiated. In consideration of its objective, which is to minimize the maximum absolute value of point coordinate component on the standard failure surface, when absolute value of each coordinate component trades off and takes turns, it cannot reach the minimum. Only when absolute values of several larger coordinate components tend to be equal, it is closer to the optimal.

Adopting adaptive step-size strategy, firstly we should get the maximum and the second maximum absolute values of coordinate component on the failure surface in the previous iteration. When the difference of the two absolute values was big, we used a larger step in the next step iteration automatically; otherwise, a smaller step-size should be adopted. The step length must be suitable to the difference of the two absolute values in the previous iteration (for convenient statement, it was expressed by $q_{(k, 1)}$ ) and the difference between the reliability indexes in previous two times iteration (it was expressed by $\left.q_{(k, 2)}\right)$. So iteration step $\alpha_{k+1}$ in the $k+1$ step could be designed as non-linear function consisting of $\mu$, $q_{(k, 1)}$ and $q_{(k, 2)}$.

$$
\alpha_{k+1}=F\left(\mu, q_{(k, 1)}, q_{(k, 2)}\right)
$$

In Eq. (9), $\mu$ was step-size coefficient. The detailed step-size strategy was shown in Fig. 2.

\subsubsection{Mutation step-size mechanism}

In early running stage of the algorithm, a large step was a benefit to jump out of local minimum point, complete global optimization task well. However, a small step can help reach the local convergence quickly in the late running. This idea could achieve great effectiveness, but it cannot solve the problem of premature convergence as dealt with complex optimization problems. When the search went into each local area, the step size was calculated according to step-size strategy in Fig. 2 on the basis of the condition of "else" or "else if". The formula does not contain adaptive mutation step-size $m$, and stepsize was only connected with step-size coefficient $\mu, q_{(k, 1)}$ and $q_{(k, 2)}$.

When the search went into local area and premature convergence appeared, variation mechanism should be lead in. Mutation step-size could help subsequent search to get rid of the local optimum, and don't stop to search into other areas of the solution space until the global optimal solution was found. Step-size was set to be the mutation step-size:

$$
\alpha_{k+1}=m
$$

In the formula (10), $m$ was adaptive mutation step length. It can be computed based on nonlinear function of iteration time $k+1, f\left(\delta_{(j+1)}\right)$ and $f\left(\delta_{(j)}\right)$.

$$
m=h\left(k+1, f\left(\delta_{(j)}\right), f\left(\delta_{(j+1)}\right)\right)
$$

In the formula (11), the $f\left(\delta_{(j+1)}\right)$ is reliability indexes of current iteration as premature convergence appears, and the $f\left(\delta_{(j)}\right)$ is reliability indexes of the previous iteration.

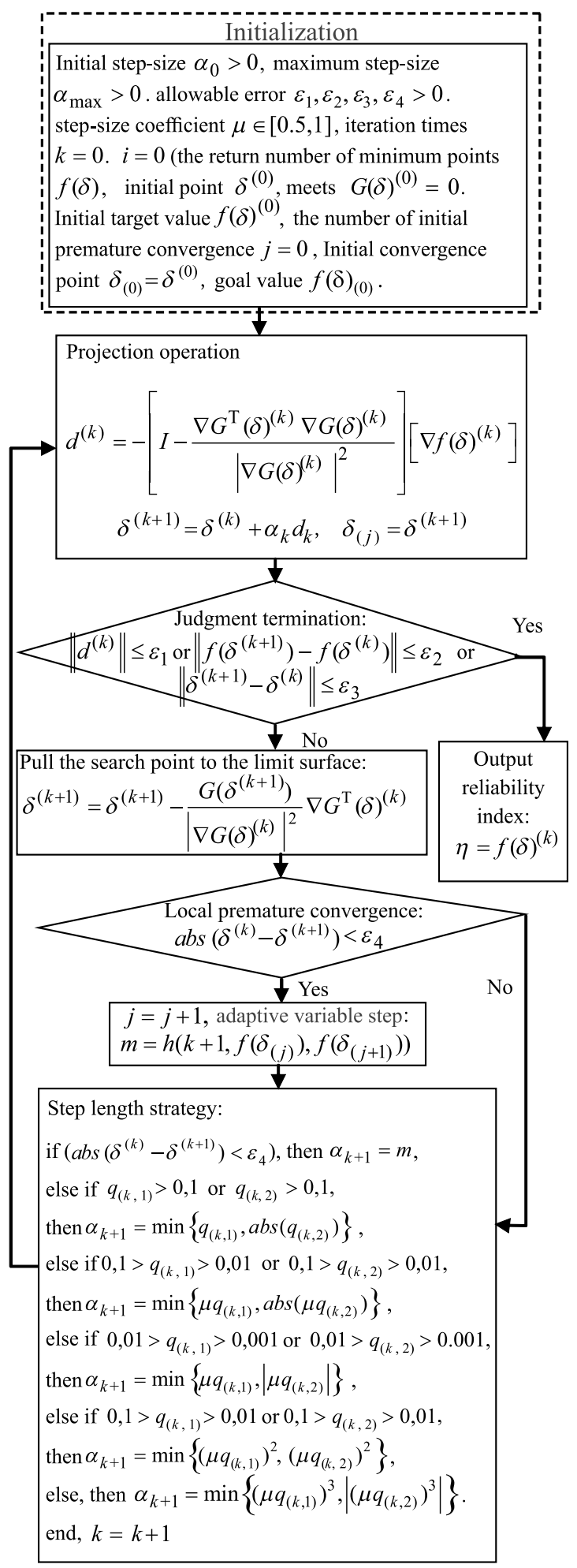

Figure 2 Step-size strategy and algorithm flow diagram 
When premature convergence appears in the process of solution space search, non-linear approaches of adaptive mutation step length can help that search jumps out of local search area effectively and achieves optimization in other areas. When getting to the next area, step-size will update in non-linear way according to the formula (9), so as to take into account both local performance and global search ability. Taking advantage of interaction of adaptive step-size strategy and mutation step-size mechanism, the way which nonlinearly controls step-length of gradient project algorithm in the process of solution space search, can effectively coordinate global and local optimization capacities of the algorithm.

\section{Numerical calculation examples \\ 4.1 Calculation example 1}

There was a quadratic non-linear performance function denoted as $G(\delta)=\left(\delta_{1}-7 / 4\right)^{2}+\left(\delta_{2}-4 / 5\right)-$ $4 \delta_{3}+5,5$. The points $D_{1}(1,51712 ; 1,51712 ; 1,51712)$ and
$D_{2}(3,03288 ; 3,03288 ; 3,03288)$ were its limit state surface $G(\delta)=0$ crossed the hyperline $\delta_{1}=\delta_{2}=\delta_{3}$ which passed through two points of the $C_{\delta}^{\infty}$ 's origin and $C_{\left|\delta_{i}\right| \leq 1}^{n}$ 's vertex. The two points located in the angular points of multi-dimensional hypercube box model, which was composed of the standardized interval variables. Due to $3,03288>1,51712, D_{2}$ should be rejected. According to the one-dimensional optimization algorithm in literature [17], the most probable failure point was $D_{1}, \eta=$ 1,51712 . However, in fact, it was not the case.

Point $(2,475 ; 0,8 ; 1,5)$ was selected as the initial point on the surface $G(\delta)=0$. To set up parameters as $\mu=0,2$ and $\varepsilon_{1}=\varepsilon_{2}=\varepsilon_{3}=\varepsilon_{4}=10^{-5}$, in terms of the step-size strategy and algorithm flow. The search process is shown in Tab. 1 .

Table 1 Search iterative process of calculation example 1

\begin{tabular}{|c|c|c|c|c|c|c|c|}
\hline Iteration time & $\delta_{1}$ & $\delta_{2}$ & $\delta_{3}$ & Reliability index $\eta$ & $\begin{array}{c}\text { Step size } \\
\alpha_{k}\end{array}$ & Local premature convergence & $\begin{array}{c}\text { Adaptive variable } \\
\text { step } m\end{array}$ \\
\hline 0 & 2,457 & 0,8 & 1,5 & 2,457 & Initial point & & \\
\hline 1 & 1,5403 & 0,8000 & 1,3860 & 1,5403 & 0,9570 & & \\
\hline 2 & 1,3883 & 0,8000 & 1,4077 & 1,4077 & 0,1543 & & \\
\hline 3 & 1,3917 & 0,8000 & 1,4071 & 1,4071 & 0,0194 & & \\
\hline 4 & 1,3917 & 0,8000 & 1,4071 & 1,4071 & $1,2254 \mathrm{e}-04$ & Yes & \\
\hline 5 & 1,4047 & 0,8000 & 1,4048 & 1,4048 & 0,075 & Global optimum & 0,075 \\
\hline
\end{tabular}

As shown in the Tab. 1, search was only conducted in surface $\delta_{2}=0,8$. The point was $(1,3917 ; 0,8 ; 1,4071)$ in the third and fourth iteration. At this moment, the local premature convergence arose, and search should be cut off in this point. It could be considered that $\eta=1,4071$, and the relative error was $(1,4071-1,4048) / 1,4048=$ $0,1637 \%$. In the next step of iteration, mutation step-size mechanism should be started. To set mutation step length as 0,075 , subsequent search got rid of local optimum quickly. It searched other areas of solution space, and the search cut-off at point $(1,4047 ; 0,8 ; 1,4048)$ in the fifth iteration. The global optimal was found and the reliability index was $\eta=1,4048$. Its component coordinates were $\delta_{1}$ $=1,4047, \delta_{2}=0,8, \delta_{3}=1,4048$, and it was not the intersection of hyperline $\delta_{1}=\delta_{2}=\delta_{3}$ and surface $G(\delta)=0$.

Table 2 Iteration process after the initial point was changed

\begin{tabular}{|c|c|c|c|c|c|c|c|}
\hline Iteration time & $\delta_{1}$ & $\delta_{2}$ & $\delta_{3}$ & Reliability index $\eta$ & $\begin{array}{c}\text { Step size } \\
\alpha_{k}\end{array}$ & Local premature convergence & $\begin{array}{c}\text { Adaptive variable } \\
\text { step } m\end{array}$ \\
\hline 0 & 1,7500 & 0 & 1,5350 & 1,7500 & Initial point & & \\
\hline 1 & 1,5350 & 0,0040 & 1,5450 & 1,5450 & 0,2150 & & \\
\hline 2 & 1,5359 & 0,0074 & 1,5435 & 1,5435 & 0,0100 & & 0,55 \\
\hline 3 & 1,5359 & 0,0075 & 1,5435 & 1,5435 & $2,8902 \mathrm{e}-04$ & & \\
\hline 4 & 1,5872 & 0,1973 & 1,4724 & 1,5872 & 0,55 & & \\
\hline 5 & 1,5438 & 0,1984 & 1,4761 & 1,5438 & 0,0437 & & \\
\hline 6 & 1,5438 & 0,1984 & 1,4761 & 1,5438 & $6,5531 \mathrm{e}-07$ & & \\
\hline 7 & 1,4450 & 0,2019 & 1,4877 & 1,4877 & 0,1 & & \\
\hline 8 & 1,4450 & 0,2019 & 1,4877 & 1,4877 & $6,2422 \mathrm{e}-07$ & & \\
\hline 9 & 1,4697 & 0,2504 & 1,4701 & 1,4701 & 0,18 & & \\
\hline 10 & 1,4698 & 0,2505 & 1,4701 & 1,4701 & $7,8789 \mathrm{e}-05$ & & \\
\hline 11 & 1,4697 & 0,2504 & 1,4701 & 1,4701 & $1,3598 \mathrm{e}-06$ & & \\
\hline 12 & 1,4697 & 0,2504 & 1,4701 & 1,4701 & $1,4533 \mathrm{e}-08$ & & \\
\hline 13 & 2,0614 & 1,4106 & 1,4925 & 2,0614 & 4,2 & & 4,2 \\
\hline 14 & 1,4936 & 1,4128 & 1,4853 & 1,4936 & 0,5689 & & \\
\hline 15 & 1,4947 & 1,4129 & 1,4852 & 1,4947 & 0,5678 & & \\
\hline 16 & 1,4853 & 1,4125 & 1,4863 & 1,4863 & 0,0095 & & \\
\hline 17 & 1,4853 & 1,4125 & 1,4863 & 1,4863 & $3,8940 \mathrm{e}-06$ & & \\
\hline 18 & 1,4859 & 1,4111 & 1,4858 & 1,4859 & 0,005 & & \\
\hline 19 & 1,4859 & 1,4111 & 1,4858 & 1,4859 & $2,5020 \mathrm{e}-05$ & & \\
\hline 20 & 1,4854 & 1,4111 & 1,4859 & 1,4859 & 0,0003 & & \\
\hline
\end{tabular}


Table 2 Iteration process after the initial point was changed (continuation)

\begin{tabular}{|c|c|c|c|c|c|c|c|}
\hline Iteration time & $\delta_{1}$ & $\delta_{2}$ & $\delta_{3}$ & Reliability index $\eta$ & $\begin{array}{c}\text { Step size } \\
\alpha_{k}\end{array}$ & Local premature convergence & $\begin{array}{l}\text { Adaptive variable } \\
\text { step } m\end{array}$ \\
\hline 21 & 1,4854 & 1,4111 & 1,4859 & 1,4859 & $1,2036 \mathrm{e}-05$ & Yes & \\
\hline 22 & 1,6387 & 1,0571 & 1,3946 & 1,6387 & 1,25 & & 1,25 \\
\hline 23 & 1,4866 & 1,0553 & 1,4086 & 1,4866 & 0,1529 & & \\
\hline 24 & 1,4874 & 1,0553 & 1,4085 & 1,4874 & 0,1521 & & \\
\hline 25 & 1,4100 & 1,0538 & 1,4200 & 1,4200 & 0,0789 & & \\
\hline 26 & 1,4104 & 1,0536 & 1,4199 & 1,4199 & 0,0020 & & \\
\hline 27 & 1,4104 & 1,0536 & 1,4199 & 1,4199 & $1,7150 \mathrm{e}-05$ & Yes & \\
\hline 28 & 1,9488 & 0,6516 & 1,3904 & 1,9488 & 3,2 & & 3,2 \\
\hline 29 & 1,4182 & 0,6529 & 1,4079 & 1,4182 & 0,5289 & & \\
\hline 30 & 1,4164 & 0,6529 & 1,4082 & 1,4164 & 0,5306 & & \\
\hline 31 & 1,4085 & 0,6530 & 1,4096 & 1,4096 & 0,0082 & & \\
\hline 32 & 1,4085 & 0,6530 & 1,4096 & 1,4096 & $2,2238 \mathrm{e}-04$ & Yes & \\
\hline 33 & 2,0035 & 0,9091 & 1,3940 & 2,0035 & 3,5 & & 3,5 \\
\hline 34 & 1,4079 & 0,9084 & 1,4072 & 1,4079 & 0,5939 & & \\
\hline 35 & 1,4062 & 0,9084 & 1,4075 & 1,4075 & 0,5956 & & \\
\hline 36 & 1,4064 & 0,9083 & 1,4074 & 1,4074 & 0,0013 & & \\
\hline 37 & 1,4062 & 0,9084 & 1,4075 & 1,4075 & $8,1073 \mathrm{e}-06$ & & \\
\hline 38 & 1,4062 & 0,9084 & 1,4075 & 1,4075 & $1,9628 \mathrm{e}-08$ & Yes & \\
\hline 39 & 1,9702 & 0,7306 & 1,3883 & 1,9702 & 3,3 & & 3,3 \\
\hline 41 & 1,4056 & 0,7312 & 1,4058 & 1,4058 & 0,5627 & & \\
\hline 42 & 1,4039 & 0,7312 & 1,4061 & 1,4061 & 0,5643 & & \\
\hline 43 & 1,4043 & 0,7313 & 1,4061 & 1,4061 & 0,0022 & & \\
\hline 44 & 1,4039 & 0,7312 & 1,4061 & 1,4061 & $1,3124 \mathrm{e}-05$ & & \\
\hline 45 & 1,4039 & 0,7312 & 1,4061 & 1,4061 & $3,5613 \mathrm{e}-07$ & Yes & \\
\hline 46 & 1,7446 & 0,7989 & 1,37501 & 1,7446 & 2,0 & & 2,0 \\
\hline 47 & 1,4062 & 0,7989 & 1,4045 & 1,4062 & 0,3385 & & \\
\hline 48 & 1,4063 & 0,7989 & 1,4045 & 1,4063 & 0,3384 & & \\
\hline 49 & 1,4046 & 0,7989 & 1,4048 & 1,4048 & 0,0018 & Global optimum optimum & \\
\hline
\end{tabular}

Obviously, to solve non-probabilistic reliability by dimensionality reduction search has limitation, which can be verified by the results in literature [6]. However, its iterations had 15 times in literature [6]. And if it didn't use space dimension reduction method and appeared local premature convergence, the search couldn't get rid of local optimum automatically, also couldn't get the global optimal finally. It led to the phenomenon that the most probable failure point calculated by the algorithm in literature [6] depended on the selection of initial point.

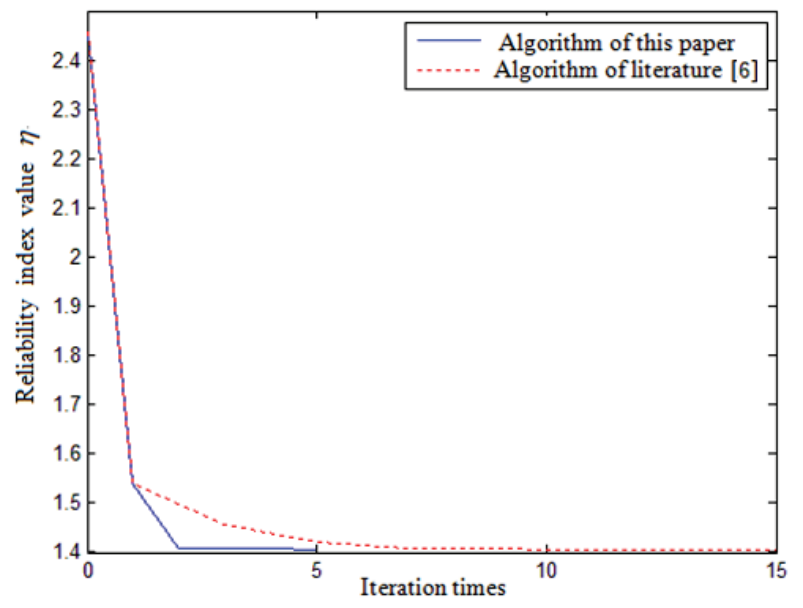

Figure 3 This paper's search process and results compared with literature [6]

For example, $(1,75 ; 0,1 ; 1,535)$ was selected for initial point, the final search point could be got at point $(1,4069 ; 0,7014 ; 1,4069)$. So the reliability index was $\eta=$ 1,4069 . Although the value was close to global optimal, there were still accuracy errors. In example 1, Fig. 3 shows this paper's search process and results compared with literature [6].

Similarly, if initial point was chosen at another point $(1,75 ; 0,1 ; 1,535)$ for calculation example 1 in literature [6], this paper's algorithm iterated 49 steps, and eventually the search ended on the global optimal point $(1,4046 ; 0,7989 ; 1,4048)$, as shown in Tab. 2. There was still $\eta=1,4048$. It was in accordance with the previous case that the initial point was set at $(2,475 ; 0,8 ; 1,5)$. Its excellent accuracy was proved. Meanwhile, it illustrated the algorithm was not sensitive to the initial point, and had good robustness.

\subsection{Calculation example 2}

Assuming $g(r, s, h)=567 r s-0,5 h^{2}$ was a non-linear performance function. In the function, $r \in[0,528 ; 0,672]$, $s \in[2,071 ; 2,289]$ and $h \in[31,16 ; 0,34,44]$ were irrelevant interval variables. The basic interval variables were standardized: $r=0,6+0,072 \delta_{r}, s=2,18+0,109 \delta_{s}$ and $h=32,8+1,64 \delta_{h}$. The standardized variables were substituted into the performance function, and standardized failure surface could be got as: $G\left(\delta_{r}, \delta_{s}, \delta_{h}\right)=$ $203,716+88,99632 \delta_{r}+37,0818 \delta_{s}+4,449816 \delta_{r} \delta_{s}-$ $53,792 \delta_{h}-1,3448\left(\delta_{h}\right)^{2}=0$. To choose $(2,5 ;-6,4979 ; 2)$ as initial point in limit state surface, iteration process was shown in Tab. 3. It illustrated that there were 18 times of local premature convergences in the search process. They were respectively shown as follows:

Iterative search point of the $25^{\text {th }}$ iteration was $(-0,7621 ;-0,6747 ; 2,0033)$, and it deemed $\eta=2,0033$; 
Iterative search point of the $36^{\text {th }}$ iteration was $(-1,3677 ;-1,1474 ; 0,8453)$, and it deemed $\eta=1,3677$; Iterative search point of the $44^{\text {th }}$ iteration was $(-1,1867 ;-1,1868 ; 1,0923)$, and it deemed $\eta=1,1868$; Iterative search point of the $48^{\text {th }}$ iteration was $(-1,2237 ;-0,9728 ; 1,1569)$, and it deemed $\eta=1,2237$; Iterative search point of the $52^{\text {th }}$ iteration was

$(-1,2183 ;-0,9763 ; 1,1631)$, and it deemed $\eta=1,2183$; Iterative search point of the $54^{\text {th }}$ iteration was

$(-1,1996 ;-0,9880 ; 1,1842)$, and it deemed $\eta=1,1996$; Iterative search point of the $58^{\text {th }}$ iteration was

$(-1,1893 ;-0,9954 ; 1,1954)$, and it deemed $\eta=1,1954$; Iterative search point of the $67^{\text {th }}$ iteration was

$(-1,2450 ;-1,0877 ; 1,0613)$, and it deemed $\eta=1,2450$; Iterative search point of the $71^{\text {th }}$ iteration was

$(-1,1609 ;-1,1406 ; 1,1564)$, and it deemed $\eta=1,1609$; Iterative search point of the $73^{\text {th }}$ iteration was

$(-1,1571 ;-1,1430 ; 1,1605)$, and it deemed $\eta=1,1605$; Iterative search point of the $77^{\text {th }}$ iteration was

$(-1,1578 ;-1,1432 ; 1,1594)$, and it deemed $\eta=1,1594$; Iterative search point of the $81^{\text {th }}$ iteration was

$(-1,1584 ;-1,1435 ; 1,1584)$, and it deemed $\eta=1,1584$; Iterative search point of the $85^{\text {th }}$ iteration was

$(-1,1600 ;-1,1446 ; 1,1554)$, and it deemed $\eta=1,1600$;
Iterative search point of the $87^{\text {th }}$ iteration was $(-1,1578 ;-1,1460 ; 1,1579)$, and it deemed $\eta=1,1579$;

Iterative search point of the $91^{\text {th }}$ iteration was $(-1,1643 ;-1,1504 ; 1,1458)$, and it deemed $\eta=1,1643$;

Iterative search point of the $95^{\text {th }}$ iteration was $(-1,1557 ;-1,1557 ; 1,1555)$, and it deemed $\eta=1,1557$;

Iterative search point of the $99^{\text {th }}$ iteration was $(-1,1556 ;-1,1555 ; 1,1557)$, and it deemed $\eta=1,1557$;

Iterative search point of the $100^{\text {th }}$ iteration was $(-1,1557 ;-1,1555 ; 1,1556)$, and it deemed $\eta=1,1557$.

To launch adaptive variable step-size mechanism in the next step of all the above 18 times of local premature convergence, eventually the search ended at the $100^{\text {th }}$ iterative search point $(-1,1556 ;-1,1556 ; 1,1556)$. The global optimal was achieved, and the reliability index was $\eta=1,1556$. It is equal to the results that combined gradient projection algorithm with dimension reduction search in literature [6].

To change search starting point position many times, all searches ended in the global optimal point $(-1,1556$; $-1,1556 ; 1,1556)$. It further illustrated that this paper's algorithm had better robustness.

Table 3 Search and iterative process of example 2

\begin{tabular}{|c|c|c|c|c|c|c|c|}
\hline $\begin{array}{l}\text { Iteration } \\
\text { time }\end{array}$ & $\delta_{r}$ & $\delta_{s}$ & $\delta_{r}$ & $\begin{array}{l}\text { Reliability } \\
\text { index } \eta\end{array}$ & $\begin{array}{c}\text { Step size } \\
\alpha_{k}\end{array}$ & $\begin{array}{c}\text { Local } \\
\text { premature } \\
\text { convergence }\end{array}$ & $\begin{array}{c}\text { Adaptive } \\
\text { variable } \\
\text { step } m\end{array}$ \\
\hline 0 & 2,5 & $-6,4979$ & 2 & 6,4979 & Initial point & & \\
\hline 1 & 0,4512 & $-0,1544$ & 4,0178 & 4,0178 & 7,9874 & & \\
\hline 2 & $-0,3475$ & $-0,5079$ & 2,6951 & 2,6951 & 1,9069 & & \\
\hline 3 & $-0,4697$ & $-0,5579$ & 2,4919 & 2,4919 & 0,2893 & & \\
\hline 4 & $-0,5556$ & $-0,5927$ & 2,3487 & 2,3487 & 0,2033 & & \\
\hline 5 & $-0,6161$ & $-0,6170$ & 2,2476 & 2,2476 & 0,1432 & & \\
\hline 6 & $-0,6588$ & $-0,6340$ & 2,1762 & 2,1762 & 0,1011 & & \\
\hline 7 & $-0,6890$ & $-0,6459$ & 2,1257 & 2,1257 & 0,0714 & & \\
\hline 8 & $-0,7104$ & $-0,6544$ & 2,0899 & 2,0899 & 0,0505 & & \\
\hline 9 & $-0,7255$ & $-0,6603$ & 2,0646 & 2,0646 & 0,0358 & & \\
\hline 10 & $-0,7362$ & $-0,6645$ & 2,0467 & 2,0467 & 0,0253 & & \\
\hline 11 & $-0,7438$ & $-0,6675$ & 2,0340 & 2,0340 & 0,0179 & & \\
\hline 12 & $-0,7492$ & $-0,6696$ & 2,0250 & 2,0250 & 0,0127 & & \\
\hline 13 & $-0,7530$ & $-0,6711$ & 2,0186 & 2,0186 & 0,0090 & & \\
\hline 14 & $-0,7557$ & $-0,6722$ & 2,0141 & 2,0141 & 0,0064 & & \\
\hline 15 & $-0,7576$ & $-0,6729$ & 2,0109 & 2,0109 & 0,0045 & & \\
\hline 16 & $-0,7590$ & $-0,6735$ & 2,0086 & 2,0086 & 0,0032 & & \\
\hline 17 & $-0,7599$ & $-0,6738$ & 2,0070 & 2,0070 & 0,0023 & & \\
\hline 18 & $-0,7606$ & $-0,6741$ & 2,0059 & 2,0059 & 0,0016 & & \\
\hline 19 & $-0,7611$ & $-0,6743$ & 2,0050 & 2,0050 & 0,0011 & & \\
\hline 20 & $-0,7614$ & $-0,6744$ & 2,0045 & 2,0045 & $8,0956 \mathrm{e}-04$ & & \\
\hline 21 & $-0,7617$ & $-0,6745$ & 2,0041 & 2,0041 & $5,7390 \mathrm{e}-04$ & & \\
\hline 22 & $-0,7618$ & $-0,6746$ & 2,0038 & 2,0038 & $4,0685 \mathrm{e}^{-04}$ & & \\
\hline 23 & $-0,7620$ & $-0,6746$ & 2,0036 & 2,0036 & $2,8842 \mathrm{e}-04$ & & \\
\hline 24 & $-0,7621$ & $-0,6747$ & 2,0034 & 2,0034 & $2,0447 \mathrm{e}^{-04}$ & & \\
\hline 25 & $-0,7621$ & $-0,6747$ & 2,0033 & 2,0033 & $1,4495 \mathrm{e}^{-04}$ & Yes & \\
\hline 26 & $-1,5972$ & $-1,0019$ & 0,5780 & 1,5972 & 2,0 & & 2,0 \\
\hline 27 & $-1,4516$ & $-1,0942$ & 0,7486 & 1,4516 & 0,4061 & & \\
\hline 28 & $-1,3985$ & $-1,1279$ & 0,8099 & 1,3985 & 0,1456 & & \\
\hline 29 & $-1,3790$ & $-1,1403$ & 0,8323 & 1,3790 & 0,0531 & & \\
\hline 30 & $-1,3718$ & $-1,1448$ & 0,8406 & 1,3718 & 0,0195 & & \\
\hline 31 & $-1,3692$ & $-1,1465$ & 0,8436 & $-1,3692$ & 0,0072 & & \\
\hline 32 & $-1,3682$ & $-1,1471$ & 0,8447 & 1,3682 & 0,0026 & & \\
\hline 33 & $-1,3679$ & $-1,1473$ & 0,8451 & 1,3679 & $9,7230 \mathrm{e}-04$ & & \\
\hline 34 & $-1,3677$ & $-1,1474$ & 0,8453 & 1,3677 & $3,5813 \mathrm{e}-04$ & & \\
\hline
\end{tabular}


Table 3 Search and iterative process of example 2 (continuation)

\begin{tabular}{|c|c|c|c|c|c|c|c|}
\hline $\begin{array}{l}\text { Iteration } \\
\text { time }\end{array}$ & $\delta_{r}$ & $\delta_{s}$ & $\delta_{r}$ & $\begin{array}{l}\text { Reliability } \\
\text { index } \eta\end{array}$ & $\begin{array}{c}\text { Step size } \\
\alpha_{k}\end{array}$ & $\begin{array}{c}\text { Local } \\
\text { premature } \\
\text { convergence }\end{array}$ & $\begin{array}{c}\text { Adaptive } \\
\text { variable } \\
\text { step } m \\
\end{array}$ \\
\hline 35 & $-1,3677$ & $-1,1474$ & 0,8453 & 1,3677 & $1,3192 \mathrm{e}-04$ & & \\
\hline 36 & $-1,3677$ & $-1,1474$ & 0,8453 & 1,3677 & $4,8591 \mathrm{e}-05$ & Yes & \\
\hline 37 & $-1,1636$ & $-1,2753$ & 1,0766 & 1,2753 & 0,55 & & 0,55 \\
\hline 38 & $-1,1856$ & $-1,1913$ & 1,0915 & 1,1913 & 0,0924 & & \\
\hline 39 & $-1,1862$ & $-1,1887$ & 1,0919 & 1,1887 & 0,0029 & & \\
\hline 40 & $-1,1865$ & $-1,1876$ & 1,0921 & 1,1876 & 0,0012 & & \\
\hline 41 & $-1,1866$ & $-1,1871$ & 1,0922 & 1,1871 & $5,2113 \mathrm{e}-04$ & & \\
\hline 42 & $-1,1867$ & $-1,1869$ & 1,0923 & 1,1869 & $2,2229 \mathrm{e}-04$ & & \\
\hline 43 & $-1,1867$ & $-1,1868$ & 1,0923 & 1,1868 & $9,4816 \mathrm{e}-05$ & & \\
\hline 44 & $-1,1867$ & $-1,1868$ & 1,0923 & 1,1868 & $4,0443 \mathrm{e}-05$ & Yes & \\
\hline 45 & $-1,2455$ & $-0,9591$ & 1,1321 & 1,2455 & 0,25 & & 0,25 \\
\hline 46 & $-1,2237$ & $-0,9728$ & 1,1569 & 1,2237 & 0,0587 & & \\
\hline 47 & $-1,2237$ & $-0,9728$ & 1,1569 & 1,2237 & $1,2907 \mathrm{e}-06$ & & \\
\hline 48 & $-1,2237$ & $-0,9728$ & 1,1569 & 1,2237 & $2,3980 \mathrm{e}-07$ & Yes & \\
\hline 49 & $-1,2193$ & $-0,9757$ & 1,1620 & 1,2193 & 0,012 & & 0,012 \\
\hline 50 & $-1,2184$ & $-0,9762$ & 1,1629 & 1,2184 & 0,0022 & & \\
\hline 51 & $-1,2183$ & $-0,9763$ & 1,1631 & 1,2183 & $4,1456 \mathrm{e}-04$ & & \\
\hline 52 & $-1,2183$ & $-0,9763$ & 1,1631 & 1,2183 & $7,7078 \mathrm{e}-05$ & Yes & \\
\hline 53 & $-1,1996$ & $-0,9880$ & 1,1842 & 1,1996 & 0,05 & & 0,05 \\
\hline 54 & $-1,1996$ & $-0,9880$ & 1,1842 & 1,1996 & $4,5856 \mathrm{e}-07$ & Yes & \\
\hline 55 & $-1,1885$ & $-0,9951$ & 1,1969 & 1,1969 & 0,03 & & 0,03 \\
\hline 56 & $-1,1890$ & $-0,9953$ & 1,1959 & 1,1959 & 0,0014 & & \\
\hline 57 & $-1,1892$ & $-0,9954$ & 1,1956 & 1,1956 & $4,9221 \mathrm{e}-04$ & & \\
\hline 58 & $-1,1893$ & $-0,9954$ & 1,1954 & 1,1954 & $1,7602 \mathrm{e}-04$ & Yes & \\
\hline 59 & $-1,3158$ & $-1,0430$ & 0,9807 & 1,3158 & 0,3 & & 0,3 \\
\hline 60 & $-1,2713$ & $-1,0711$ & 1,0315 & 1,2713 & 0,1204 & & \\
\hline 61 & $-1,2548$ & $-1,0815$ & 1,0502 & 1,2548 & 0,0445 & & \\
\hline 62 & $-1,2487$ & $-1,0854$ & 1,0572 & 1,2487 & 0,0165 & & \\
\hline 63 & $-1,2464$ & $-1,0868$ & 1,0598 & 1,2464 & 0,0061 & & \\
\hline 64 & $-1,2455$ & $-1,0874$ & 1,0608 & 1,2455 & 0,0023 & & \\
\hline 65 & $-1,2452$ & $-1,0876$ & 1,0611 & 1,2452 & $8,5190 \mathrm{e}-04$ & & \\
\hline 66 & $-1,2451$ & $-1,0876$ & 1,0613 & 1,2451 & $3,1729 \mathrm{e}-04$ & & \\
\hline 67 & $-1,2450$ & $-1,0877$ & 1,0613 & 1,2450 & $1,1818 \mathrm{e}-04$ & Yes & \\
\hline 68 & $-1,1629$ & $-1,1393$ & 1,1541 & 1,1629 & 0,22 & & 0,22 \\
\hline 69 & $-1,1612$ & $-1,1404$ & 1,1559 & 1,1612 & 0,0044 & & \\
\hline 70 & $-1,1609$ & $-1,1406$ & 1,1563 & 1,1609 & $8,2799 \mathrm{e}-04$ & & \\
\hline 71 & $-1,1609$ & $-1,1406$ & 1,1564 & 1,1609 & $1,5595 \mathrm{e}-04$ & Yes & \\
\hline 72 & $-1,1571$ & $-1,1430$ & 1,1606 & 1,1606 & 0,01 & & 0,01 \\
\hline 73 & $-1,1571$ & $-1,1430$ & 1,1605 & 1,1605 & $1,3365 \mathrm{e}-04$ & Yes & \\
\hline 74 & $-1,1576$ & $-1,1431$ & 1,1598 & 1,1598 & 0,001 & & 0,001 \\
\hline 75 & $-1,1577$ & $-1,1432$ & 1,1595 & 1,1595 & $3,5667 \mathrm{e}-04$ & & \\
\hline 76 & $-1,1578$ & $-1,1432$ & 1,1594 & 1,1594 & $1,2722 \mathrm{e}-04$ & & \\
\hline 77 & $-1,1578$ & $-1,1432$ & 1,1594 & 1,1594 & $4,5376 \mathrm{e}-05$ & Yes & \\
\hline 78 & $-1,1582$ & $-1,1434$ & 1,1587 & 1,1587 & 0,001 & & 0,001 \\
\hline 79 & $-1,1583$ & $-1,1434$ & 1,1585 & 1,1585 & $2,3761 \mathrm{e}-04$ & & \\
\hline 80 & $-1,1583$ & $-1,1434$ & 1,1585 & 1,1585 & $8,4751 \mathrm{e}-05$ & & \\
\hline 81 & $-1,1584$ & $-1,1435$ & 1,1584 & 1,1584 & $3,0229 \mathrm{e}-05$ & Yes & \\
\hline 82 & $-1,1605$ & $-1,1443$ & 1,1549 & 1,1605 & 0,005 & & 0,005 \\
\hline 83 & $-1,1601$ & $-1,1445$ & 1,1553 & 1,1601 & 0,0010 & & \\
\hline 84 & $-1,1600$ & $-1,1445$ & 1,1554 & 1,1600 & $1,9201 \mathrm{e}-04$ & & \\
\hline 85 & $-1,1600$ & $-1,1446$ & 1,1554 & 1,1600 & $3,6174 \mathrm{e}-05$ & Yes & \\
\hline 86 & $-1,1577$ & $-1,1460$ & 1,1579 & 1,1579 & 0,006 & & 0,006 \\
\hline 87 & $-1,1578$ & $-1,1460$ & 1,1579 & 1,1579 & $9,4255 \mathrm{e}-05$ & Yes & \\
\hline 88 & $-1,1662$ & $-1,1492$ & 1,1436 & 1,1662 & 0,02 & & 0,02 \\
\hline 89 & $-1,1647$ & $-1,1502$ & 1,1454 & 1,1647 & 0,0042 & & \\
\hline 90 & $-1,1644$ & $-1,1504$ & 1,1457 & 1,1644 & $7,8813 \mathrm{e}-04$ & & \\
\hline 91 & $-1,1643$ & $-1,1504$ & 1,1458 & 1,1643 & $1,4845 \mathrm{e}-04$ & Yes & \\
\hline 92 & $-1,1556$ & $-1,1559$ & 1,1555 & 1,1559 & 0,023 & & 0,023 \\
\hline 93 & $-1,1557$ & $-1,1558$ & 1,1555 & 1,1557 & $1,1722 \mathrm{e}-04$ & & \\
\hline 94 & $-1,1557$ & $-1,1557$ & 1,1555 & 1,1557 & $5,0003 \mathrm{e}-05$ & & \\
\hline
\end{tabular}




\begin{tabular}{|c|c|c|c|c|c|c|c|}
\hline $\begin{array}{l}\text { Iteration } \\
\text { time }\end{array}$ & $\delta_{r}$ & $\delta_{s}$ & $\delta_{r}$ & $\begin{array}{l}\text { Reliability } \\
\text { index } \eta\end{array}$ & $\begin{array}{c}\text { Step size } \\
\alpha_{k}\end{array}$ & $\begin{array}{c}\text { Local } \\
\text { premature } \\
\text { convergence }\end{array}$ & $\begin{array}{c}\text { Adaptive } \\
\text { variable } \\
\text { step } m\end{array}$ \\
\hline 95 & $-1,1557$ & $-1,1557$ & 1,1555 & 1,1557 & $2,1330 \mathrm{e}-05$ & Yes & \\
\hline 96 & $-1,1558$ & $-1,1554$ & 1,1556 & 1,1558 & 0,0003 & & 0,0003 \\
\hline 97 & $-1,1557$ & $-1,1554$ & 1,1556 & 1,1557 & $2,6487 \mathrm{e}^{-05}$ & & \\
\hline 98 & $-1,1557$ & $-1,1555$ & 1,1556 & 1,1557 & 0,00015 & & \\
\hline 99 & $-1,1556$ & $-1,1555$ & 1,1557 & 1,1557 & $1,5000 \mathrm{e}^{-}-04$ & Yes & \\
\hline 100 & $-1,1557$ & $-1,1555$ & 1,1556 & 1,1557 & 0,00015 & Yes & 0,00015 \\
\hline 101 & $-1,1556$ & $-1,1556$ & 1,1556 & 1,1556 & 0,00015 & Global & 0,00015 \\
\hline
\end{tabular}

By contrast, the gradient projection algorithm was solely adopted in calculation example 2 in literature [6]. Its search ended in the local premature convergence point $[-1,1631 ;-1,1229 ; 1,1631]$. The reliability index was $\eta=$ 1,1631 and error was $0,649 \%$. In literature [6], the subsequent search is made equal to the first component absolute value and the third component of the absolute value, i.e. $\delta_{r}=-\delta_{h}$. That could be reduced to a twodimensional search. At last, search ended in $[-1,1556$; $-1,1556]$ and reached the target point. To be sure, the method is artistic, but the most dangerous point must be limited at the angular points of multi-dimensional hypercube box model, which is composed of the standardized interval variables. In fact, it is doubtful that all of the most dangerous points are in those locations. So it does not have a universal significance. Furthermore, the reason that search end at non-target points is not taking adaptive variable step-size mechanism. It leads, that the gradient project algorithm cannot effectively jump out of local optimal area.

\section{Conclusions}

Because of the simple algorithm and clear mathematical meaning, gradient projection algorithm can be widely used in the probabilistic reliability analysis. This paper established adaptive step-size strategy and adaptive mutation step-size mechanism. The strategy had non-linear relationship with step-size coefficient $\mu$, the difference $q_{(k, 1)}$ of the maximum and second maximum absolute value of coordinate components in the previous iteration, and the difference $q_{(k, 2)}$ of reliability indexes in the previous two iterations. Similarly, the mechanism had non-linear relationship with iteration time $k+1$, the reliability index $f\left(\delta_{(j+1)}\right)$ as appeared premature convergence in the current iteration, and the reliability index $f\left(\delta_{(j)}\right)$ as appeared premature convergence in the previous iteration.

The strategy and mechanism could automatically make a large step in infancy of gradient projection algorithm, while making a small step in the steady state. At the same time, step-size could mutate automatically when it fell into the local state of premature convergence. It could effectively help the subsequent search to seek for optimization in other areas.

Experiments showed that the proposed algorithm in this paper controlled iteration step-size by adaptive stepsize strategy and adaptive mutation step-size mechanism. Compared with simple gradient projection algorithm, it has faster convergence speed and higher accuracy. Taking local and global search performance capacities into consideration, it showed the advantages of being effective and practical in solving problems of non-probabilistic reliability index.

\section{Acknowledgements}

This work was funded by The National Natural Science Foundation of China (No. 51465017).

\section{References}

[1] Ma, Dongjuan; Liu, Boying; Li, Lingling. Non-probabilistic Reliability Analysis Method Based on Interval Analysis. // Journal of Mechanical Strength. 37, 1(2015), pp. 84-87.

[2] Jiang, Chong; Zhou, Keping. Analysis on Reliability of Pier Foundation Based on Interval Theory. // Journal of the China Railway Society. 36, 2(2014), pp. 116-121.

[3] Angelis, M. D.; Patelli, E.; Beer, M. Advanced Line Sampling for efficient robust reliability analysis. // Structural Safety. 52, 1(2015), pp. 170-182. DOI: 10.1016/j.strusafe.2014.10.002

[4] Chernyaev, Y. A. Convergence of the gradient projection method and Newton's method as applied to optimization problems constrained by intersection of a spherical surface and a convex closed set. // Computational Mathematics \& Mathematical Physics. 56, 10(2016), pp. 1716-1731. DOl: 10.1134/S0965542516100055

[5] Yin, Hang; Li, Shijun; Li, Xiaozhen. The Application of Gradient Projection Method in Non-probabilistic Reliability. // Chinese Journal of Applied Mechanics. 29, 6(2012), pp. 717-722.

[6] Li, Shi-Jun; Fan, Jian-Ping; Qi, Wei; Chen, Xu-Yong. The gradient projection method for non-probabilistic reliability index based on interval model. // Chinese Journal of Computational Mechanics. 30, 2 (2013):192-197.

[7] Liu, Chengli. Research on Reliability Analysis and Design of Complex Structure. // (2006) Xi'an, China: Xi'an Technological University.

[8] Guo, S. X.; Lv, Z. Z. Interval arithmetic and static interval finite element method. // Applied Mathematics and Mechanies. 22, 12(2001), pp. 1390-1396. DOI: 10.1023/A:1022826525318

[9] Cauchy, A. Method Generale Pour La Resolution des Systems D'Equations Simultaneous. // Comp. Rend. Sci. Paris. 25, (1847), pp. 536-538.

[10] Barzilai, J.; Borwein, J. M. Two-point step size gradient methods. // IMA Journal of Numerical Analysis. 8, 1(1988), pp. 141-148. DOI: 10.1093/imanum/8.1.141

[11] Dai, Y. H. Alternate step gradient method Optimization. // A Journal of Mathematics Programming and Operations Research. 52, 4(2003), pp. 395-415.

[12] Hestenes, M. R.; Stiefel, E. Method of conjugate gradient for solving linear equations. // Res. Nat. Bur. Stand. 49, 6(1952), pp. 409-436. DOI: 10.6028/jres.049.044 
[13] Fletcher, R.; Reeves, C. Function minimization by conjugate gradients. // Computer Journal. 7, 2(1964), pp. 149-154. DOI: 10.1093/comjnl/7.2.149

[14] Yuan, G. L. Modified nonlinear conjugate gradient methods with sufficient descent property for large-scale optimization problems. // Optimization Letters. 3, 1(2009), pp. 11-21. DOI: 10.1007/s11590-008-0086-5

[15] McCormick, G. P.; Tapia, R. A. The gradient projection method under mild differentiability conditions. // SIAM Journal on Control. 10, 1(1972), pp. 93-98. DOl: 10.1137/0310009

[16] Hager, W. W.; Park, S. The gradient projection method with exact line search. //J Global Optim. 30, 1(2004), pp. 103-118. DOI: 10.1023/B:JOGO.0000049118.13265.9b

[17] Jiang, Tao; Chen, Jianjun; Jiang, Peigang et al. A Onedimensional Optimization Algorithm for Non-probabilistic Reliability Index. // Engineering Mechanics. 24, 7(2007), pp. 23-27.

\section{Authors' addresses}

Zhaoping Tang, PhD candidate and professor

1) School of Traffic \& Transportation Engineering, Central South

University, Changsha Hunan, China

2) School of Information Engineering, East China Jiao Tong

University, Nanchang Jiangxi, China

No. 808 Shuanggang East Avenue Nanchang Jiangxi, 330013,

China

E-mail: tzp@ecjtu.jx.cn

\section{Jin Qin, Dr and professor}

School of Traffic \& Transportation Engineering, Central South University, Changsha Hunan, China

School of railway, Central South University, No. 68 Shaoshan

South Road, Changsha Hunan, 410075, China

E-mail: qinjin@csu.edu.cn

\section{Jianping Sun, Dr and professor}

School of Railway Transportation, East China Jiao Tong

University, Nanchang Jiangxi, China

No. 808 Shuanggang East Avenue Nanchang Jiangxi, 330013,

China

E-mail: 928135125@qq.com

\section{Biao Geng, master student}

School of Railway Transportation, East China Jiao Tong

University, Nanchang Jiangxi, China

No. 808 Shuanggang East Avenue Nanchang Jiangxi, 330013,

China

E-mail: 2444495051@qq.com 